\title{
O ESTUDO DO ADVÉRBIO NAS SENTENÇAS DO PORTUGUÊS BRASILEIRO
}

Glaucia do Carmo Xavier Instituto Federal de Minas Gerais

Arabie Bezri Hermont Pontifícia Universidade Católica

Isadora Pereira do Couto Instituto Federal de Minas Gerais

\section{RESUMO}

Este artigo pretende demonstrar resultados de uma pesquisa que procurou investigar se o posicionamento do advérbio não é livre. Ancorado na Teoria Gerativa, este trabalho tem como hipótese que determinados advérbios ocupam, grande parte das vezes, posições fixas na sentença. Cinque (1999) e Rocha \& Lopes (2015) são autores que fundamentam também o quadro teórico desta pesquisa e demonstram, de modos distintos, que determinados advérbios mantêm-se em posições fixas em sentenças. Outros advérbios, no entanto, não têm posição tão fixa. Esta pesquisa, por meio de análise de transcrição de falas reais, investigou e tabulou 548 advérbios presentes em diálogos de falantes nativos do português brasileiro e classificou dezoito tipos de advérbios e suas respectivas posições. O corpus foi construído a partir de gravações de aulas de uma escola privada, em Belo Horizonte, e trazido para esta investigação em uma abordagem qualitativa e quantitativa. Os resultados deste trabalho demonstraram que os advérbios, tradicionalmente tidos como termos acessórios da oração, podendo aparecer em diversas posições na sentença, nem sempre são livres e que determinados tipos de advérbios só se encontram em posições fixas na sentença. PALAVRAS-CHAVE: Advérbio, Posição na sentença, Teoria Gerativa. 


\section{Introdução}

Os advérbios são considerados termos acessórios de uma sentença, pois não são selecionados como argumentos de um predicador, assim são adjunções na estrutura sintática. Tendo como foco a representação sintática mental, há teóricos, como Ernst (2002), que defendem a Teoria da Adjunção, a qual postula a adjunção de advérbios onde quer que eles recebam sua interpretação, como um apêndice de um sintagma. Já a Teoria do Especificador, de Cinque (1999), é contra a ideia de que o advérbio deva ocupar posições de adjuntos, mas a favor de ele ocupar a posição de especificador de um sintagma. A partir desses pressupostos iniciais, apresentamos, neste artigo, os principais resultados de uma pesquisa cujo objetivo maior foi analisar as relações existentes entre advérbio e seu posicionamento nas sentenças, em uma abordagem formalista.

Ancorada na Teoria Gerativa, esta pesquisa postula que o advérbio de determinadas naturezas, na maioria das vezes, se posiciona fixamente em posições pré-determinadas. Nessa perspectiva, este trabalho alinha-se em parte à teoria de Cinque (1999), ainda que a pesquisa ora empreendida tenha investigado advérbios além daqueles pesquisados pelo autor. Cinque (1999) estudou advérbios modalizadores, de modo, de tempo e de aspecto. Este trabalho lidou com uma gama maior de advérbios, os quais foram citados em várias gramáticas e bibliografias que versam sobre tal constituinte.

Sabe-se que Cinque (1999) associa a posição de advérbios modalizadores, de modo, de tempo e de aspecto a núcleos funcionais correspondentes e, por isso, há a postulação de posição fixa e hierarquia de tais advérbios. Entretanto, esta pesquisa verificou outros advérbios, além daqueles já pesquisados por Cinque. O objetivo era o de verificar se o mesmo comportamento sintático ocorre com advérbios de outras categorias.

A hipótese é que advérbios nem sempre são livres e que determinados tipos de advérbios só se encontram em posições rígidas.

Para realizar tal estudo, foi feita uma pesquisa com 548 advérbios retirados de diálogos de falantes nativos do português brasileiro e verificada a relação destes com os respectivos verbos.

Este artigo organiza-se da seguinte forma: inicialmente, apresenta-se um roteiro teórico que será iniciado pela apresentação objetiva dos pressupostos da Teoria Gerativa. Em seguida, serão trazidas as postulações sobre o estudo de advérbios de Cinque (1999), Hermont e Otoni 
(2016), Xavier e Hermont (2017), Rocha e Lopes (2015) e Xavier (2016). Mais adiante, é demonstrada a metodologia. Em seguida, há os resultados alcançados e a discussão dos dados. Por fim, as considerações finais são apresentadas.

\section{Teoria Gerativa}

Para a pesquisa em gramática gerativa chomskyana, o comportamento linguístico dos indivíduos deve ser compreendido também como uma dotação genética interna ao organismo humano, pois se relaciona com um estado da mente/cérebro, independente de outros elementos no mundo. Para Chomsky (1995, p. 16), a mente "possui aspectos dedicados à linguagem - a que chamamos a sua Faculdade da Linguagem", especificamente associados à produção e à compreensão da língua. A Faculdade da Linguagem possui um estado inicial desde o nascimento de uma pessoa, denominado Gramática Universal, cuja complexidade de organização é rica e uniforme para toda a espécie humana. Durante o crescimento de todo ser humano, semelhante a qualquer outra organização fisiológica, anatômica ou mental, a Faculdade de Linguagem passa por fases em seu desenvolvimento e atinge o estado final, chamado de Língua- ${ }^{1}$, composto pelo Léxico e o Sistema Computacional, ou seja, pelo conjunto de traços fonológicos, sintáticos e semânticos e pelas operações que formam as sentenças.

A Gramática Universal é regida por princípios, os quais podem ser compreendidos como propriedades universais das línguas naturais. São os princípios que "oferecem um esquema altamente restritivo a que cada língua humana tem de se conformar, assim como condições específicas que determinam como a gramática de qualquer língua pode ser usada" (CHOMSKY, 1973, p.83). Por outro lado, os parâmetros devem ser entendidos como as possibilidades de variação entre as línguas. Assim, a proposição fundamental formulada por Chomsky é a de que a criança nasce biologicamente equipada com uma gramática, na qual se encontram todos os dispositivos que possibilitam a aquisição de uma língua natural ${ }^{2}$. A Teoria Gerativa defende a ideia de que a linguagem, complexa como é, constitui-se como uma das coisas que diferenciam os homens dos animais (HAUSER; CHOMSKY; FITCH, 2002).

Desde a década de 50, quando a teoria foi criada, os estudos gerativistas passaram por diversas modificações e reformulações. Três importantes etapas podem ser observadas: Teoria Padrão (1965), Teoria da 
Regência e Ligação (1981) e o atual Programa Minimalista (1995) e é nesta última perspectiva que este trabalho se insere.

Tem-se, a seguir, o design do Programa Minimalista para a derivação da sentença.

\section{Figura 1- Design do Programa Minimalista}

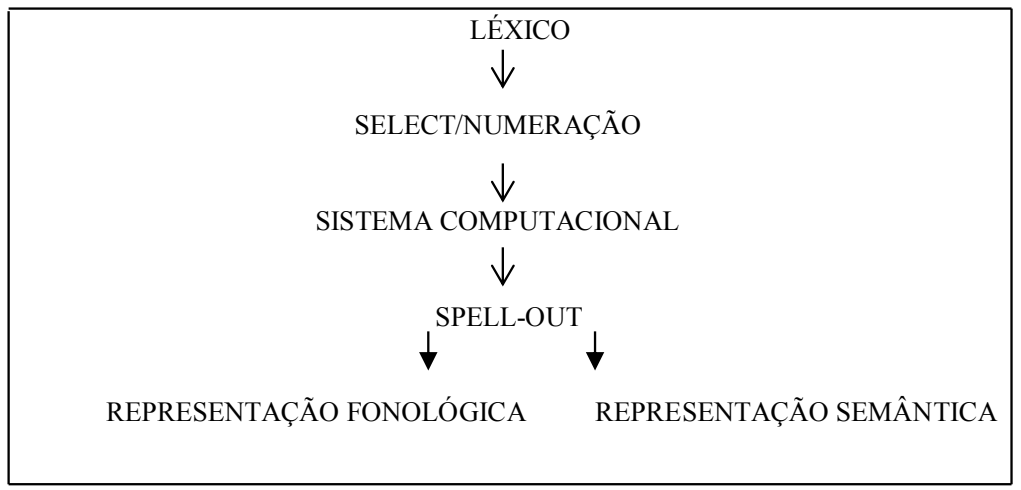

Fonte: Elaborado pelas autoras

O esquema apresentado demonstra que, a partir do Léxico que "especifica os itens que participam nas operações do sistema computacional, com as suas propriedades idiossincrásticas ${ }^{3}$ " (CHOMSKY, 1995, p.245), as categorias lexicais e funcionais são selecionadas para formar as sentenças.

As categorias lexicais, também chamadas de palavras de conteúdo, são consideradas como uma classe aberta, pois são infinitas, uma vez que é possível formar outras palavras a partir delas. As categorias lexicais correspondem, por exemplo, aos nomes, aos verbos e aos adjetivos. Já as categorias funcionais estão relacionadas à desinência, ao número, ao modo e à pessoa. Determinantes e quantificadores (artigos, pronomes, quantificadores, auxiliares, morfemas, conjunções) são também exemplos de categorias funcionais. Elas são consideradas uma classe fechada, uma vez que as palavras contidas nelas são finitas (XAVIER; MORATO, 2014).

Voltando à figura 1, essa seleção recebe o nome select e forma uma Numeração. A ideia é que esses itens já venham da Numeração com tra- 
ços definidos como traços de gênero, de número, plural, de categoria, de caso etc. Após a seleção, ocorre no Sistema Computacional a derivação das sentenças. Para que a sentença formada no Sistema Computacional seja expressa e compreendida, a operação chamada spell-out entra em ação. É ela que permite a divisão da estrutura sintática para as interfaces fonológica e semântica.

A pesquisa em gramática gerativa levanta as seguintes questões essenciais: como a gramática mental de um indivíduo é representada em sua mente? Como o conhecimento da linguagem é adquirido? Como um indivíduo põe seu conhecimento linguístico em uso? Como as propriedades relacionadas à linguagem se realizam nos mecanismos do cérebro? Para obter respostas a essas questões, a pesquisa de Chomsky apresenta uma metodologia dedutiva ${ }^{4}$. Em relação às questões acima, a presente pesquisa buscou saber como o advérbio pode ser representado na gramática mental dos indivíduos. Para isso, a hipótese deste trabalho está relacionada aos trabalhos de Cinque (1999), Hermont e Otoni (2016), Xavier e Hermont (2017), Rocha e Lopes (2015) e Xavier (2016) que acreditam que os advérbios, no momento da derivação da sentença, não ocupam qualquer posição sintática, eles parecem ter, por vezes, posições pré-estabelecidas. Essas posições parecem ter ligação com o tipo de advérbio.

Para compreender o que pode ocorrer no interior do Sistema Computacional, a pesquisa gerativista faz uso do desempenho dos falantes, a partir da análise das sentenças já produzidas. Por meio do desempenho, busca-se a competência, ou seja, a capacidade interna de produção linguística do falante.

Na próxima seção, apresentaremos as postulações sobre advérbios, necessárias à compreensão e ao desenvolvimento da pesquisa empreendida.

\section{Advérbio e sua posição sintática}

Cinque (1999) desenvolveu larga pesquisa sobre a relação dos advérbios e os sintagmas funcionais. $\mathrm{O}$ autor afirma que o advérbio não ocupa posições de adjuntos, mas de especificadores de projeções funcionais porque eles podem carregar traços de modalidade, de modo, de tempo e de aspecto, assim constituem parte integral da sentença. Se alguns advérbios podem carregar tais traços na sentença, eles não poderiam ficar à direita dos sintagmas, em suas posições finais, mas à esquerda para constituir parte integrante. 
A Teoria do Especificador, de Cinque (1999), defende que certas sequências de advérbios são rigidamente ordenadas, enquanto outras não, e que certos tipos de advérbios em todas as línguas ocorrem em áreas particulares da sentença, mais abaixo ou mais acima, por exemplo. Dessa forma, o autor acredita que os advérbios se localizam em zonas bem definidas ou há uma ordem em que eles ocorram.

Segundo Cinque (1999), os advérbios são especificadores únicos de projeções máximas e existe uma hierarquia de projeções funcionais. O primeiro exemplo que o autor apresenta é: geralmente $>$ já $>$ normalmente $>$ mesmo assim $>$ ainda não $>$ parcialmente $>$ satisfatório $>$ nem sequer $>$ ainda (CINQUE, 1999). Segundo ele, o advérbio "geralmente" estaria, com mais frequência, antes do advérbio "já", ou melhor, mais acima, quando se trata de uma representação arbórea. Da mesma forma, ocorre com os demais advérbios citados acima. Eles apareceriam com frequência, quanto mais à esquerda do sinal >, mais anteriormente eles ocorreriam nas sentenças. Porém, nesta pesquisa, não demonstraremos a hierarquia de advérbios e, sim, algumas posições sintáticas, comumente, mais fixas.

A seguir, apresentamos uma figura que corrobora o que se assume nesta pesquisa em termos de representação sintagmática, com um núcleo e o advérbio à esquerda do verbo:

Figura 2- Sintagma

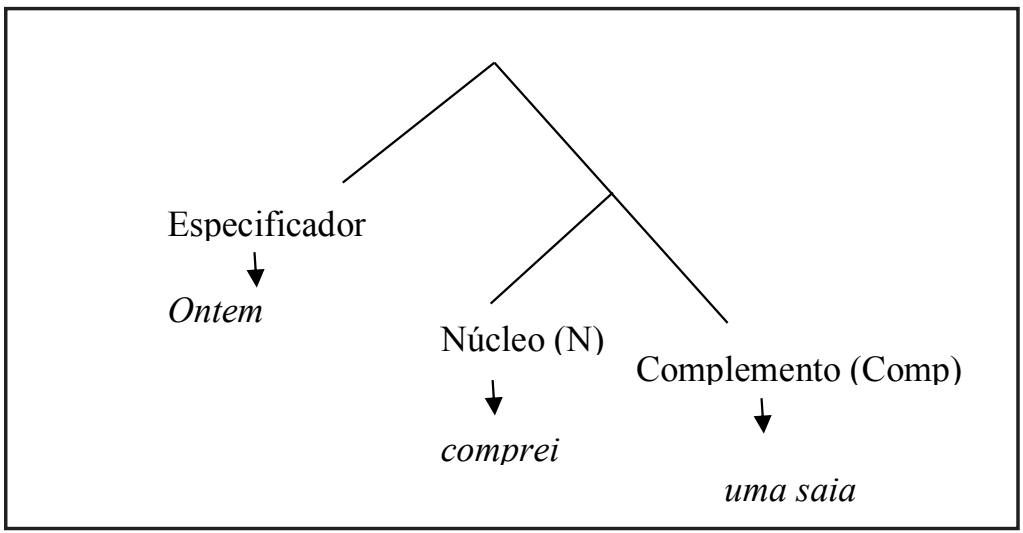

Fonte: Elaborado pelas autoras

Conforme a figura, alguns advérbios não são adjuntos, mas parte integrante da sentença, pois podem carregar traços de tempo, por isso, 
ficariam à esquerda em um sintagma funcional. Cinque (1999) afirma que pode acontecer de o advérbio ocupar diversas posições, mas é raro, o comum é reconhecer posições fixas para eles. Duas posições mais comuns para os advérbios são antes ou depois dos complementos. $\mathrm{O}$ autor assinala que os advérbios podem ser gerados independentemente nessas duas posições ou que elas são associadas a movimentos de traços no momento da derivação das sentenças no Sistema Computacional. Portanto, segundo o modelo de Cinque (1999), os advérbios só poderiam ocupar os especificadores de cada sintagma.

Alguns trabalhos realizados por componentes do grupo de pesquisa ElinC (Estudos em Linguagem e Cognição) usam esse arcabouço teórico. Um deles, de Hermont e Otoni (2016), procedeu a uma análise descritiva acerca de marcadores, que teriam função muito parecida com as de advérbios, em tétum-praça, uma das línguas faladas em Timor-Leste. Foi observado que o verbo na língua em questão ocorre na forma não flexionada e que marcadores atribuem noções de tempo e de aspecto em alguns casos. A pesquisa proporcionou uma maior compreensão das projeções funcionais no tétum-praça, do papel que têm os marcadores de natureza temporal e aspectual e sugeriu-se que tais marcadores poderiam estar localizados em posição de especificador de sintagmas funcionais.

Outro estudo, realizado por Xavier e Hermont (2017), tratou do aspecto verbal como uma categoria constituída por todo sintagma verbal, também se levou em consideração, na análise, a teoria de Cinque para validar o papel do advérbio na composição aspectual. Por exemplo, para uma sentença como "Uma vez, eu me lembro, já estava trabalhando, eu...", verificamos que temos um advérbio "já", seguido de um auxiliar no pretérito e de um verbo flexionado no gerúndio. Em Xavier e Hermont (2017), assume-se que o auxiliar teria informação aspectual [-perfectivo] que combinaria com a estrutura da sentença (cf. Wachowicz, 2006)). Além disso, as autoras alinham-se à perspectiva de Cinque (1999), o qual adota a noção de que advérbios ocupariam as posições de especificadores de projeções máximas e que pode haver vários nódulos aspectuais, cada um com uma noção distinta. Assim sendo, o verbo "trabalhar" teria sua posição final em um nódulo aspectual, o auxiliar seria inserido no núcleo de AuxP, passaria por um núcleo de AspP, localizado acima de AuxP, onde teria os traços de aspecto do auxiliar valorados e, por fim, receberia os traços de tempo no núcleo de TP. Na posição de espcificador de TP, teríamos o advérbio "já", ligado, portanto, a um nódulo de Tempo (anterior) 
nas palavras de Cinque (1999). Assim como nesse exemplo e em outros, assumiu-se a hipótese da posição do advérbio no especificador de determinados sintagmas aspectuais.

Rocha e Lopes (2015), sobre o português brasileiro, afirmam que, no momento da formação de uma sentença, o predicador pode requerer, no máximo, três argumentos, um externo (sujeito) e dois internos (complementos). No entanto, como os advérbios não são selecionados por predicadores, "não há na sintaxe nenhuma restrição quanto ao número de adjuntos que possam ocorrer em uma dada sentença, (...) contudo, há restrições dos próprios adjuntos, especialmente os advérbios, em relação ao tipo de elemento a que vão se adjungir" (ROCHA; LOPES, 2015, p. 157).

Elas defendem que alguns advérbios, como "provavelmente", podem ocorrer em várias posições, no entanto, apesar de não ditarem uma hierarquia de advérbios, como faz Cinque (1999), as autoras afirmam que:

os adjuntos, embora mais livres do que, por exemplo, os complementos, são elementos bastante bem comportados no que se refere a posições que possam ocupar na sentença, à recursividade, à proibição de movimento de elementos que os constituem (ROCHA; LOPES, 2015, p. 156).

Para elas, como os advérbios não mantêm relação de concordância e Caso com o verbo, eles não podem modificar a natureza categorial de um elemento. $\mathrm{O}$ que eles fazem é acrescentar camadas hierárquicas sobre a categoria, assim, esse processo faz criar uma nova posição estrutural no topo, quando se une a um nódulo já existente. As autoras afirmam que os advérbios podem se posicionar à esquerda ou à direita do $\mathrm{SV}$, tais como em:

(1) Maria cozinha feijão [na panela de pressão].

(2) Maria [rapidamente] cozinhou o feijão. (Rocha e Lopes, 2015, p. 159)

No entanto, essa liberdade na posição é ditada pela natureza do adjunto. Quando o advérbio marca tempo e aspecto, parece não haver liberdade, em relação à sua representação sintática, uma vez que não pode haver muita disparidade na informação dada pelo adjunto e a flexão temporal presente no Sintagma Flexional. Rocha e Lopes (2015, p.159) trazem algumas sentenças para exemplificar a afirmação dada:

(3) Ontem João chorou.

(4)* Ontem João chorou hoje.

(5) * Ontem João vai chover. (Rocha e Lopes, 2015, p. 160) 
Quanto aos advérbios aspectuais, aqueles que marcam duração do evento, as autoras afirmam que eles ocupam, preferencialmente, alguma das quatro posições: antes do verbo, entre verbo auxiliar e verbo principal, após o verbo ou após o complemento, sem perder de vista que os sentidos se alteram em função do escopo do advérbio (ROCHA; LOPES, 2015, p. 176).

(6) Pedro ainda não tinha visto o filme.

(7) Pedro não tinha ainda visto o filme.

(8) Pedro não tinha visto ainda o filme.

(9) Pedro não tinha visto o filme ainda. (Rocha e Lopes, 2015, p. 176)

Para Rocha e Lopes (2015), a posição dos advérbios é estabelecida pelo "cruzamento entre forma e função semântica dos adjuntos" (ROCHA; LOPES, 2015, p. 172). Ou seja, o advérbio é um tema em que a sintaxe e semântica precisam ser levadas em conta na definição de posições sintáticas relativamente fixas.

Baseando-se nas teorias de Cinque (1999) e Rocha e Lopes (2015), Xavier (2016) analisou sentenças do português brasileiro e considerou que alguns advérbios, na verdade, são constituídos por traços de tempo e, por vezes, eles indicam a temporalidade da sentença em detrimento da flexão verbal. Dessa forma, os advérbios precisam ocupar a posição de especificadores, uma vez que, como adjuntos, não haveria necessidade ou possibilidade de checagem de traços numa relação com os núcleos sintagmáticos. Ainda assim, admite-se que, por vezes, o advérbio possa aparecer à direita do verbo. Porém, isso ocorre quando os advérbios não apresentam efeito de escopo, como os de lugar, por exemplo. Um exemplo pode ser dado: "João leu o livro na sala", em que o SP "na sala" foi adjungido à sentença.

Xavier (2016) assinala que o advérbio pode ser marca de tempo e aspecto, assim como morfemas verbais podem codificar noções de modo, tempo e aspecto. Em sentenças como: (7) "até pouco tempo, da última, na última vez, eles estavam criando jacarés", o falante diz três diferentes advérbios, mas nenhum deles contrapõe-se ao tempo verbal de "estavam criando", ou seja, advérbio e tempo são contemporâneos. Isso indica que o advérbio precisa estar de acordo com as demais marcas de tempo da sentença e, para isso, ele precisa se movimentar pelas projeções dos sintagmas no momento da derivação da sentença. Essa parece ser uma constatação de que alguns advérbios apresentam posições fixas e rígidas. 
Vários trabalhos foram realizados com o objetivo de verificar a relação de determinados advérbios com o núcleo verbal, tal como o de Santana (2005) e de Teixeira (2015). Com a intenção de ampliar os estudos acerca do tema, esta pesquisa, conforme já assinalado na Introdução, visa a investigar se o posicionamento do advérbio não é livre. Para tanto, realizou a metodologia que passa a ser apresentada na seção seguinte.

\section{Metodologia}

Para a realização dessa pesquisa, a investigação foi dividida em três etapas. A primeira delas constituiu-se de estudos teóricos. Na segunda etapa, procurou-se identificar, na transcrição de uma aula de Educação Física em uma escola belorizontina, todos os advérbios e classificá-los em tipos gramaticais. Na terceira etapa, tabulou-se a localização de cada advérbio na sentença procurando verificar se tal constituinte ocupava a posição inicial, final, pré-verbal ou pós-verbal. Por fim, retomou-se a análise qualitativa interpretando os dados encontrados na amostra e na análise.

A parte prática da pesquisa foi construída por meio de transcrições impressas de aulas gravadas no ano de 2007. As aulas ocorreram em uma escola privada de Belo Horizonte. As turmas observadas foram de $4^{\circ}$ e $5^{\circ}$ ano. Para esta análise, foi utilizada uma aula de Educação Física. Na ocasião, ocorriam ensaios para a Festa Junina da escola, os quais foram o tema da aula transcrita. A amostra foi composta por 548 (quinhetoas e quarenta e oito) ocorrências de advérbios.

Conforme já apontado, identificamos, em cada sentença, todos os advérbios encontrados. Em seguida, esses advérbios foram tabulados e classificados em 18 (dezoito) tipos gramaticais: tempo, lugar, ordem, modo, afirmação, negação, inclusão, exclusão, dúvida, quantidade, intensidade, frequência, situação, realce, meio ou instrumento, companhia, complemento adverbial e retificação. Os tipos foram determinados por meio de pesquisa bibliográfica. Assim, todos os tipos de advérbios, citados em gramáticas, como Cegalla (2010, 259-260) e Bechara (2006, p. 290-291) e literaturas sobre o tema, tais como Ilari et al. (in Castilho, 2002, 53-120), Ilari (in Ilari, 2002, p. 139-180) e Neves (in Ilari, 2002, p. 249-286), foram abarcados pela pesquisa.

Posteriormente, esses advérbios foram classificados em uma das quatro possíveis localizações na sentença: (1) primeira ou (2) última palavra ou se estavam em posição (3) pré ou (4) pós-verbal. Após essa classificação, esses dados foram quantificados em números absolutos e relativos, em relação ao posicionamento dos advérbios nas sentenças. 
Por fim, retomamos à transcrição e à revisão da literatura e realizamos análise qualitativa interpretando os dados encontrados. Toda a análise foi feita levando em conta, sempre, o suporte da Teoria Gerativa que explica a formação das sentenças e a representação mental de cada categoria no momento dessa formação. A seguir, apresentamos os resultados e a discussão dos dados encontrados.

\section{Resultados e Discussões}

Para a apresentação dos resultados, exporemo-los, no primeiro momento, em uma tabela geral e, em seguida, eles serão comentados um a um, por meio de tópicos. Alguns exemplos serão trazidos para melhor compreensão dos resultados.

Tabela 1- Classificação, quantificação e posição dos advérbios

\begin{tabular}{|c|c|c|c|c|c|}
\hline $\begin{array}{l}\text { CLASSIFICAÇÃO } \\
\text { GRAMATICAL DOS } \\
\text { ADVÉRBIOS }\end{array}$ & $\begin{array}{l}\text { TOTAL DE } \\
\text { ADVÉRBIOS } \\
\text { NA AMOSTRA }\end{array}$ & $\begin{array}{l}\text { POSIÇÃO } \\
\text { PRÉ- } \\
\text { VERBAL }\end{array}$ & $\begin{array}{l}\text { POSIÇÃO } \\
\text { PÓS- } \\
\text { VERBAL }\end{array}$ & $\begin{array}{l}\text { POSIÇÃO } \\
\text { INICIAL }\end{array}$ & $\begin{array}{l}\text { POSIÇÃO } \\
\text { FINAL }\end{array}$ \\
\hline TEMPO & 51 & $\begin{array}{c}12 \mathrm{OU} \\
23,53 \%\end{array}$ & $\begin{array}{c}9 \mathrm{OU} \\
17,65 \%\end{array}$ & $\begin{array}{l}19 \mathrm{OU} \\
37,25 \%\end{array}$ & $\begin{array}{l}11 \mathrm{OU} \\
21,57 \%\end{array}$ \\
\hline LUGAR & 228 & $\begin{array}{l}14 \mathrm{OU} \\
6,14 \%\end{array}$ & $\begin{array}{c}68 \mathrm{OU} \\
29,82 \%\end{array}$ & $\begin{array}{l}20 \mathrm{OU} \\
8,77 \%\end{array}$ & $\begin{array}{l}126 \mathrm{OU} \\
55,26 \%\end{array}$ \\
\hline ORDEM & 3 & - & - & $\begin{array}{c}1 \mathrm{OU} \\
33,33 \%\end{array}$ & $\begin{array}{c}2 \mathrm{OU} \\
66,67 \%\end{array}$ \\
\hline MODO & 49 & $\begin{array}{c}1 \mathrm{OU} \\
2,04 \%\end{array}$ & $\begin{array}{l}20 \mathrm{OU} \\
40,82 \%\end{array}$ & $\begin{array}{l}1 \mathrm{OU} \\
2,04 \%\end{array}$ & $\begin{array}{l}27 \mathrm{OU} \\
55,10 \%\end{array}$ \\
\hline AFIRMAÇÃO & 4 & $1 \mathrm{OU} 25 \%$ & - & $1 \mathrm{OU} 25 \%$ & 2 OU $50 \%$ \\
\hline NEGAÇÃO & 111 & $\begin{array}{c}56 \mathrm{OU} \\
50,45 \%\end{array}$ & $\begin{array}{l}7 \mathrm{OU} \\
6,30 \%\end{array}$ & $\begin{array}{c}31 \mathrm{OU} \\
27,93 \%\end{array}$ & $\begin{array}{c}17 \mathrm{OU} \\
15,32 \%\end{array}$ \\
\hline INCLUSÃO & 13 & $\begin{array}{l}1 \mathrm{OU} \\
7,69 \%\end{array}$ & $\begin{array}{c}5 \mathrm{OU} \\
38,46 \%\end{array}$ & $\begin{array}{c}2 \mathrm{OU} \\
15,38 \%\end{array}$ & $\begin{array}{c}6 \mathrm{OU} \\
46,15 \%\end{array}$ \\
\hline EXCLUSÃO & 22 & $\begin{array}{l}2 \mathrm{OU} \\
9,09 \%\end{array}$ & $\begin{array}{l}14 \mathrm{OU} \\
63,64 \%\end{array}$ & $\begin{array}{c}6 \mathrm{OU} \\
27,27 \%\end{array}$ & - \\
\hline DÚVIDA & 0 & - & - & - & - \\
\hline QUANTIDADE & 2 & - & $\begin{array}{l}2 \mathrm{OU} \\
100 \%\end{array}$ & - & - \\
\hline INTENSIDADE & 20 & - & $\begin{array}{l}16 \mathrm{OU} \\
80 \%\end{array}$ & - & 4 OU $20 \%$ \\
\hline ASPECTUAL & 16 & - & $\begin{array}{c}6 \mathrm{OU} \\
37,5 \%\end{array}$ & $\begin{array}{c}6 \mathrm{OU} \\
37,5 \%\end{array}$ & 4 OU $25 \%$ \\
\hline SITUAÇÃO & 10 & - & - & $\begin{array}{l}10 \mathrm{OU} \\
100 \%\end{array}$ & - \\
\hline REALCE & 3 & - & $\begin{array}{c}2 \mathrm{OU} \\
66,67 \%\end{array}$ & - & $\begin{array}{c}1 \mathrm{OU} \\
33,33 \%\end{array}$ \\
\hline $\begin{array}{l}\text { MEIO OU } \\
\text { INSTRUMENTO }\end{array}$ & 2 & - & $\begin{array}{l}2 \mathrm{OU} \\
100 \%\end{array}$ & - & - \\
\hline COMPANHIA & 2 & - & $1 \mathrm{OU} 50 \%$ & - & 1 OU $50 \%$ \\
\hline $\begin{array}{l}\text { COMPLEMENTO } \\
\text { ADVERBIAL }\end{array}$ & 11 & - & $\begin{array}{c}2 \mathrm{OU} \\
18,18 \%\end{array}$ & - & $\begin{array}{c}9 \mathrm{OU} \\
81,82 \%\end{array}$ \\
\hline RETIFICAÇÃO & 1 & - & - & $\begin{array}{l}1 \mathrm{OU} \\
100 \%\end{array}$ & - \\
\hline
\end{tabular}

Fonte: Elaborada pelas autoras 


\section{Advérbio de tempo}

O advérbio de tempo, com 51 (cinquenta e uma) ocorrências na amostra, pareceu ter um comportamento mais livre, pois ocupa as quatro posições sem diferenças significativas de quantidade entre essas localizações sintáticas. A diferença quantitativa da ocorrência do advérbio de tempo em posição inicial (37,25\%), posição pré-verbal $(23,53 \%)$, pós-verbal $(17,65 \%)$ ou posição final $(21,57 \%)$ é pequena. Ainda assim, esse dado confirma a postulação teórica de que o advérbio de tempo ocupa a posição de especificador de cada sintagma da sentença. Interessante notar que cada advérbio expressa uma noção distinta de tempo. Daí a possibilidade de ocupar posições diferentes na sentença.

Ex:

$(30)^{5}$ Depois você cumprimenta a plateia.

(84) Pelo amor de Deus, já tirei a ponte.

Por exemplo, "depois" denota noção de tempo futuro e "já" de tempo passado. Na teoria de Cinque, o primeiro advérbio ocupa posição distinta do segundo.

\section{Advérbio de lugar}

Sobre os advérbios de lugar, obtiveram-se 228 (duzentas e vinte e oito) ocorrências na amostra. Dessas, 55,26\% ocorreram como última palavra da sentença. Essa quantidade foi um destaque porque apenas 8,77\% ocorreram como primeira palavra da sentença. Constatar que os advérbios de lugar aparecem menos como primeira palavra do que como última é uma consideração importante. Conclui-se que é mais comum um advérbio de lugar aparecer em posição final. Após o verbo, o advérbio aparece em $29,82 \%$ das ocorrências e antes do verbo $6,14 \%$. Assim, se somarmos as ocorrências da posição pós-verbal, mais as ocorrências da posição final, o resultado será $85,08 \%$. Esse dado também reforça a teoria apresentada de que os advérbios de lugar são adjungidos próximos aos complementos que são os elementos a que eles se unem.

Ex:

(63) Atrás? Então mudou.

(25) Aqui você está ficando com isto, aqui?

Parece, portanto, que o advérbio de lugar é um componente que é adjungido ao sintagma verbal. 


\section{Advérbio de modo}

Os advérbios de modo ocorreram 49 (quanrenta e nove) vezes na amostra. Em relação a eles, há um resultado relevante, pois $95,92 \%$, ou seja, quase $96 \%$ de todos os advérbios de modo ocorreram na segunda metade da sentença, sendo que $40 \%$ apareceram logo após o verbo e $55 \%$ como a última palavra da sentença. Esse dado é muito significativo, uma vez que se pode concluir que os advérbios de modo quase sempre ocorrem depois do verbo. Para uma representação sintática, esse dado é relevante.

Ex:

(190) As meninas põem a mão na frente, igual estava antes.

(4) Professor! Professor! A culpa não é minha. É sempre dos meus irmãos. Meu irmão chega assim. Eu dou um tapa na cara dele.

(37) Como assim? Foi mal.

\section{Advérbio de negação}

Os advérbios de negação obtiveram 111 (cento e onze) ocorrências em nossa pesquisa. Sendo que $50,45 \%$ deles apareceram em posição pré-verbal. No entanto, se somarmos os $50,45 \%$ advérbios presentes logo antes do verbo, mais os $27,93 \%$ deles ocupando a posição de primeira palavra da sentença, tem-se $78,38 \%$ dos advérbios de negação ocorrendo no início da sentença. Pode-se constatar que esses advérbios aparecem, comumente, na primeira metade da sentença e apenas $21,62 \%$ aparecem em posição pós-verbal ou final.

Ex:

(6) Eu não conheço ninguém.

(11) Não fala, Fred! Não fala, Fred!

(46) Não pode pegar bola nenhuma ali não viu Luiza, nem corda, nem nada.

Esses resultados corroboram a proposta de uma posição fixa para determinados advérbios. No caso dos advérbios de negação, não há previsão na hierarquia de Cinque (1999), mas esse componente já é estudado desde Pollock (1989), pesquisa em que se configura como um sintagma em posição fixa na estrutura sintática.

\section{Advérbio de inclusão/ exclusão}

Se somarmos os advérbios de inclusão e exclusão, eles aparecem 35 (trinta e cinco) vezes. Mas, se os separarmos, têm-se 13 (treze) ocor- 
rências para o de inclusão e 22 (vinte e duas) para o de exclusão. Esse número pequeno, abaixo de 30 (trinta) ocorrências, não oferece segurança matemática para pesquisas científicas, conforme afirmam Guy e Zilles (2007). Ainda assim, os dados obtidos serão apresentados. Os advérbios de inclusão ocorrem na maioria das vezes após o verbo e como última palavra da sentença. Em relação aos advérbios de exclusão, observa-se que a maioria aparece após o verbo $(63,64 \%)$, pois, em 22 (vinte e duas) ocorrências, nenhuma delas apareceu como última palavra da sentença, $9,09 \%$ ocorreram em posição pré-verbal e $27,27 \%$ em posição inicial.

Ex:

(210) Se não quiser ensaiar vamos para a sala, ficamos na sala e pronto, aula também não tem não.

(9) Vou chamar mais uma pessoa.

(28) Eu estudei no colégio Santa Marcelina e ela também.

(116) Vamos lá que só falta o túnel.

\section{Vl Advérbio de intensidade}

Os advérbios de intensidade apareceram 20 (vinte) vezes na amostra. Apesar do número 20 ser menor que o ideal para uma análise quantitativa científica, observou-se que $80 \%$, que é uma quantidade significativa para esta análise, ocorreram logo após o verbo e os outros quatro, ou seja, $20 \%$ ocorreram como última palavra da sentença. Nesta amostra, os advérbios de intensidade apareceram apenas na segunda metade das sentenças.

Ex:

(7) Catarina, eu não conheço. Ela vai ser muito difícil.

(48) Gente, essa roda não pode abrir mais.

\section{VIl Advérbio de Aspecto}

Os advérbios aspectuais de frequência apareceram em apenas 16 (dezesseis) ocorrências. O que se pode constatar é que nenhum advérbio de frequência apareceu logo antes do verbo, porém 37,5\% apareceram em posição inicial da sentença, enquanto $62,5 \%$ apareceram posição final ou pós-verbal. Não se pode fazer uma conclusão sobre os advérbios aspectuais de frequência, mas os dados demonstram que parece ser mais comum os advérbios de frequência ocorrerem na segunda metade das frases. Essa constatação corrobora a teoria de Cinque (1999), em que os adverbios aspectuais de repetição ficam em posição mais abaixo na hierarquia das categroias funcionais. 
Ex:

(89) Vou fazer de novo a cobra. Vamos fazer direito. Olha a cobra!

(114) De novo! Não deixa buraco na roda.

(30.1) Fila para ensaiar uma vez.

\section{V11l Advérbio de situação}

Sobre os advérbios de situação, que geralmente são os advérbios “afinal, agora, então", percebemos que eles ocorrem apenas em posição inicial da sentença. Entretanto, obtivemos apenas 10 (dez) ocorrências desse tipo, o que não nos leva a uma conclusão, pois não tivemos mais de 30 dados.

Ex: (25) Aqui, você está ficando com isto aqui?

\section{Advérbios como complemento adverbial}

A pesquisa incluiu, dentre os advérbios, o complemento adverbial. Isso é importante, uma vez que o verbo "ir" necessita de complemento que indique lugar. Baseamos nossa afirmação em Saraiva (1983) que demonstra inúmeras ocorrências sobre casos como os encontrados na pesquisa e afirma que complementos verbais de lugar, após o verbo "ir", devem ser considerados complemento adverbial. Nesta amostra, obtivemos 11(onze) ocorrências de complemento adverbial, um número abaixo do ideal para uma conclusão científica. No entanto, $81,82 \%$ deles, nove dos onze, aparecem como sendo a última palavra da sentença, e os outros dois, ou seja, $18 \%$ aparecem após o verbo.

Ex:

(125) Vamos lá para outra parte, obrigada, Valentina.

(74) Dama (vai) pro lado direito.

$X$ Advérbios de ordem, quantidade, realce, meio ou instrumento, companhia, retificação e dúvida

Esses advérbios apareceram em quantidade inferior ao desejável: uma a três ocorrências em toda a amostra. Isso nos leva a não apresentar nenhuma conclusão sobre eles.

Sobre o adverbio de dúvida, não houve nenhuma ocorrência. Não é possível apresentar exemplos do texto utilizado nesse item, pois não encontramos na análise nenhum advérbio de dúvida. Os advérbios de dúvida na pesquisa teórica foram considerados os advérbios seguintes: acaso, 
porventura, possivelmente, provavelmente, quiçá, talvez, eventualmente e decerto. Essas palavras não são encontradas com frequência no vocabulário infantil e a nossa gravação foi de uma aula de Educação Física com crianças do quinto ano que têm, em média, dez anos de idade. Sabe-se que o advérbio "talvez" é muito comum, ainda assim ele não ocorreu. Tomamos esse fato como curiosidade da nossa pesquisa.

Ex:

(118) Eu quero andar primeiro, Pedro Henrique. (ORDEM)

(316) A turma de vocês tem menos trio. (...) Eu vou explicar porque todo mundo que me escuta obedece, escuta e obedece, só que vocês não concentram, vocês ficam brincando. (QUANTIDADE/ REALCE)

(325) Sei lá. (REALCE)

(36) Ô, Frederico, você não quer fazer, está gastando tempo, pega com a mão, também, né, Fred. (INSTRUMENTO)

(353) Vamos quarta série, todo mundo tem que chegar junto. (COMPANHIA)

(288) Aliás, faz o seguinte, solta a mão e fica só os trios de mãos dadas, fica só o trio. (RETIFICAÇÃO)

\section{Considerações Finais}

A pesquisa teve como objetivo avaliar se que o advérbio é, conforme alguns teóricos afirmam (CINQUE,1999; HERMONT E OTONI, 2016; XAVIER E HERMONT, 2017; ROCHA E LOPES, 2015; XAVIER, 2016), uma categoria com posicionamento rígido nas sentenças. A amostra constitutiva da pesquisa foi composta por transcrições de aulas gravadas de uma escola de Belo Horizonte - Minas Gerais. Foram identificados todos os advérbios dessas transcrições, depois foram classificados conforme o seu tipo gramatical e o posicionamento na sentença. Por fim, os dados foram quantificados em números absolutos e relativos, resultando em uma análise qualitativa desses dados.

A pesquisa chega ao fim, confirmando que alguns advérbios, de fato, ocupam posições mais fixas na nossa gramática mental. Os advérbios de lugar e os complementos adverbiais, assim como frequência, modo, intensidade, inclusão e exclusão aparecem mais na segunda metade das sentenças, em posições pós-verbais e finais. Já os advérbios de negação e afirmação, em sua grande maioria, estão presentes nas posições pré-verbais e iniciais. Os advérbios de tempo se posicionaram de forma mais equilibrada nas quatro posições da sentença. Entretanto, vale dizer 
que os tipos de advérbios de tempo são variados, o que pode justificar a possibilidade de aparecerem em posições distintas, em relação ao verbo.

Não obstante, os dados demonstram que, no momento da derivação da sentença, em nossa gramática mental, conforme a descrição da Teoria Gerativa, os advérbios de tempo, de negação e de aspecto parecem ocupar a posição de especificador de sintagma funcional. Isso acontece porque eles parecem ocupar posições mais rígidas e ter uma relação estreita com o verbo. Outros tipos de advérbios não seriam meros termos acessórios e, sim, cumpririam função de complemento verbal. Por fim, outros advérbios, como os de lugar, parecem ser adjungidos à estrutura sintática, onde quer que eles sejam requeridos.

Portanto, pode-se afirmar que, apesar de os advérbios serem considerados termos acessórios, pois não são requeridos pelo predicador, isso não quer dizer que podem ocupar livremente qualquer posição na sentença. Esta pesquisa demonstrou que alguns advérbios ocupam posições fixas nas sentenças. Há alguns que se posicionam na primeira metade da dela, posicionando-se antes do verbo ou ocupando a posição de primeira palavra. Há outros que se encontram mais facilmente na segunda metade da sentença, como a última palavra ou em uma posição pós-verbal. Alguns advérbios como os de lugar podem até se posicionar à direita dos sintagmas, pois são considerados adjuntos. No entanto, os advérbios de tempo e aspecto precisam se posicionar à esquerda dos sintagmas e ocupar o especificador de projeção máxima devido à valoração de traços no momento da derivação das sentenças. 


\section{STUDY OF THE POSITIONING OF THE ADVERBS IN BRAZILIAN PORTUGUESE SENTENCES}

This paper aims to demonstrate results of research that sought to investigate whether the positioning of adverbs is free or not. Anchored in the Generative Theory, the hypothesis of this work is that certain adverbs occupy, in most cases, fixed positions in a sentence. Cinque (1999) and Rocha \& Lopes (2015) are authors that also support the theoretical framework of this research and demonstrate, in different ways, that certain adverbs remain in fixed positions in sentences. Other adverbs, however, have no fixed position. This research, through a transcription analysis of real speech, investigated and categorized 548 adverbs present in dialogues of native speakers of Brazilian Portuguese and classified eighteen types of adverbs and their respective positions. The corpus was built from recordings of lessons from a private school in Belo Horizonte, and was brought to this research for both qualitative and quantitative analyses. The results of this work demonstrated that adverbs, traditionally considered as accessory terms to a clause, which can appear in several positions in a sentence, are not always free and that certain types of adverbs appear only in fixed positions in the sentence.

KEYWORDS: Adverb, Position in sentence, Generative Theory.

NOTAS

1 "Podemos considerar que a lingua-I tem duas componentes: um léxico e um sistema de princípios (regras, operações) chamamos Sistema Computacional (da linguagem humana)"(Chomsky, 1995, p.18).

${ }^{2}$ A língua natural é o sistema de comunicação verbal que se desenvolve espontaneamente no interior de uma comunidade (ex.: português, inglês, japonês, italiano etc.).

3 “Estas propriedades incluem a representação da forma fonológica de cada item, 
a especificação de sua categoria sintática, e as suas características semânticas" (CHOMSKY, 1995, p. 70)

${ }^{4}$ Método científico que considera a conclusão como implícita nas premissas e o conhecimento como não dependente da experiência para confirmar respostas. Geralmente, parte-se de um conhecimento geral para o particular.

${ }^{5}$ Os exemplos serão numerados conforme a numeração e ordem das sentenças da aula transcrita.

\section{REFERÊNCIAS}

CINQUE, Guglielmo. Adverbs and functional heads: a cross-linguistics perspective. New York: Oxford University Press, 1999.

CHOMSKY, Noam. The minimalist program. Cambridge: MIT Press, 1995.

CHOMSKY, Noam. Linguagem e Pensamento. Tradução de Francisco M. Guimarães. 3.ed. Petrópolis: Vozes, 1973.

ERNST, Thomas. The Syntax of Adjuncts, Cambridge Univ. Press, Cambridge. 2002.

GUY, G. R. \& A. ZILLES: Sociolinguística Quantitativa: Instrumental de análise. São Paulo: Parábola Editorial, 2007.

HAUSER, Marc D.; CHOMSKY, Noam; FITCH, W. Tecumseh. The Faculty of Language: What is it, Who has it, and How did it envolve? SCIENCE , New York, v. 298, p. 1569-1579, nov. 2002.

ILARI, RODOLFO. Sobre os advérbios aspectuais. In: ILARI, Rodolfo (Org.). Gramática do Português Falado. $4^{\mathrm{a}}$ ed. Vol: II: Níveis de análise linguística. Campinas, SP: Editora da Unicamp, 2002. Cap. 8, p. 139-180.

ILARI, RODOLFO et al. Considerações sobre a posição dos advérbios. In: Castilho, Ataliba Teixeira (Org.). Gramática do Português Falado. $4^{\mathrm{a}}$ ed. Vol: I. Campinas, SP: Editora da Unicamp, 2002. Cap. 2, p. 53-120.

NEVES, Maria Helena Moura. Os advérbios circunstanciais. In: ILARI, Rodolfo (Org.). Gramática do Português Falado. $4^{\mathrm{a}}$ ed. Vol: II: Níveis de análise linguística. Campinas, SP: Editora da Unicamp, 2002. Cap. 8, p. 139-180.

HERMONT, Arabie Bezri; OTONI, Jean dos Santos. As categorias tempo e aspecto e sua relação com marcadores na língua tétum-praça. Revista Linguística, UFRJ, Rio de Janeiro, v.12, n. 2, 2016. 
POLLOCK, Jean-Yves. Verb movement, universal grammar, and the structure of IP. Linguistic Inquiry, v. 20, n. 3, p. 365-425, 1989.

ROCHA, Maura A. Freitas; LOPES, Ruth E. Vasconcellos. Adjunção. IN: KATO, Mary A. ; NASCIMENTO, Milton do. A construção da sentença: Gramática do português culto falado no Brasil. São Paulo: Contexto, 2015.

SANTANA, M. Sintaxe do advérbio. 2005. Dissertação (Mestrado)_Universidade Federal do Rio de Janeiro, Rio de Janeiro, 2005.

SARAIVA, Maria Elizabeth Fonseca. Verbo "transitivo adverbial: uma mera questão de rótulo?" Caligrama: Revista de Estudos Românicos, UFMG, Belo horizonte, n.2, 1983.

TEIXEIRA, Zenaide Dias. Propriedades sintáticas e semânticas dos advérbios no Português brasileiro. 2015. 173 f. Tese (Doutorado em Linguística)-Universidade de Brasília, Brasília, 2015.

XAVIER, Gláucia do Carmo; MORATO, Rodrigo A. Teoria Gerativa: uma introdução aos principais conceitos. IN: HERMONT, A. B. (Org.) ; XAVIER, G. C. (Org.) . Gerativa: (inter)faces de uma teoria. 1. ed. Florianópolis: Beconn - produção de conteúdo, 2014.

XAVIER, Gláucia do Carmo. O estudo do aspecto em uma perspectiva minimalista: representação sintática e relações com categorias funcionasis e lexicais. Tese (Doutorado em Línguística e Língua Portuguesa)- Faculdade de Letras, Pontifícia Universidade Católica. Belo Horizonte, 2016.

XAVIER, Gláucia do carmo; HERMONT, Arabie Bezri. Interpretação aspectual na relação entre verbo, complementos verbais e advérbios. Percursos Linguisticos, UFES, Vitória (ES), v.7, n.16, 2017.

WACHOWICZ, Tereza Cristina; FOLTRAN, Maria José. Sobre a noção de aspecto. Caderno de Estudos Linguísticos. Campinas, 48(2), p. 211-232, 2006.

Recebido: 25/01/2018

Aceito: 10/06/2018 